\title{
From the Air: the photographic record of Florida's lands
}

Stephanie C. Haas, haas@uflib.ufl.edu

Erich Kesse, kesse@ufl.edu

Mark Sullivan, marsull@uflib.ufl.edu

Randal Renner, ranrenn@uflib.ufl.edu

Digital Library Center, University of Florida Libraries

Joe Aufmuth, mapper@ufl.edu

GIS Coordinator, Documents Department, University of Florida Libraries

Support staff for project, http://www.uflib.ufl.edu/digital/collections/FLAP/Credits.htm

\section{BACKGROUND}

Historical aerial photographs dramatically document changes in Florida's land use. Between 1938 and 1971, the U.S. Department of Agriculture (U.S.D.A.) created more than 88,000 black and white, 9 × 9 aerial photographs with 2,500 accompanying photomosaic indexes (19381971) of Florida. Flight lines were county based and each flight created dozens of individual aerial photographs, or tiles. Due to the unstable nature of the photographic negative's sodium nitrate composition, the U.S. government destroyed archival negatives for the earliest photos. As a result, the aging hardcopy photographic prints are all that remain of this historic resource. Originally intended to assist farmers determine accurate assessments for their farms and to provide information on crop determination and soil conservation, today these images provide some of the oldest land use/cover information available. They are used extensively in agriculture, conservation, urbanization, recreation, education, hydrology, geology, land use, ecology, geography, and history.

The University of Florida Map \& Digital Imagery Library houses the largest and most complete collection of Florida aerial photographs ( 160,000 photos) outside of the National Archives in Washington, D.C. U.S.D.A. aerial photographs $(-120,000)$ comprise the largest and most heavily used single set of photographs in this collection. In 2002, the Digital Library Center, the Map \& Digital Imagery Library, and the GIS Coordinator, Federal Documents Department of the University of Florida Libraries submitted a grant proposal to the Florida Department of State, Division of Library and Information Services to digitize the aging 1937-1951 images and make then available over the Web through an ESRI map server. The grant was funded as an LSTA grant in 2002; Phase II funded in 2003 digitized the tiles from 1952-1970. The project site can be found at http://www.uflib.ufl.edu/digital/collections/flap.

\section{INTRODUCTION}

Within Florida, government agencies and private consulting firms have made extensive use of the UF collection. But few citizens and fewer educators and students recognize the many potential uses of these early historical images that document Florida's transition from rural to urban, track the containment of Florida's terrestrial waters, or trace its phenomenal growth as a "sunshine" mecca. Although physically accessible, these images remained Florida's hidden visual heirloom.

Once the project content was defined, we sought to document the need by soliciting input from the Florida community. To do this, we targeted GIS and other email lists, asking individuals to forward the message to others who might be interested in such a project. Within five days, we 
had received over 90 responses that reflected serious interest from a wide, diverse user base. Support came from Federal, state, and local agencies; Florida industries for which land use is an intrinsic factor; educators of students in grades 1-12; nonprofit organizations with interests ranging from environment to genealogy; and non-affiliated individuals with personal interests.

The comments of Mark W. Glisson, Environmental Administrator, Division of State Lands of Florida clearly indicate the tremendous need for and interest in this project:

"It is my understanding that the Digital Library Center and the Map \& Imagery Center, University of Florida Libraries, are currently pursuing a grant to digitize and make available on the Web the historical Florida aerial photographs, taken by the USDA between 1937 and 1955. As Staff Director for the Acquisition \& Restoration Council, and as director of the office responsible for reviewing land management plans, proposed land uses, and reviewing management activities on all conservation lands leased for management by the Board of Trustees in Florida, please allow me to lend my enthusiastic support and encouragement for this endeavor.

More than 8 million acres, or approximately $25 \%$ of Florida's total upland acreage, are managed for conservation purposes. Included among those responsible for managing these conservation lands are the state agencies that manage state parks, state forests, wildlife management areas and greenways, federal agencies such as the U.S. Forest Service, U.S. Fish \& Wildlife Service National Park Service and even the Department of Defense, the five state water management districts, and a growing number of NGOs and local governments. Common among all of these land managers is an increasing emphasis on restoring Florida's natural systems to some semblance of their natural state. For the first time ever, the Florida Forever land acquisition program now includes a focus on restoration funding, in recognition of the fact that we may now finally be in a position to not only set aside remaining "natural" areas, but to proactively pursue the return of these mostly-altered systems to functioning habitat and wetland systems.

In order to collectively work toward this goal, there is a genuine need for a consensus on the objectives and desired outcomes of restoration initiatives, so that different agencies and different funding sources are not in conflict when lands lie in common watersheds or on adjacent uplands. Uniform access to these historical aerials could help immensely in guiding restoration objectives and identifying historical water flows and habitat characteristics, across agency and management boundaries.

Beyond this role as a "standardizer" and data source for large-scale restoration, the maps would also provide invaluable and quickly-accessed information for any land manager seeking through accepted land management practices to restore natural functions and flow patterns on conservation lands. As a land manager for 18 years with the state park system, I can tell you from firsthand experience that such a tool could go a long way toward taking the guesswork out of management objectives. In addition, the historical land uses and working landscapes revealed by 
these aerials could help managers protect and interpret Florida's rich cultural heritage."

Because there is a nation-wide emphasis on restoration of native landscapes, a high level of support for similar projects in other states is highly probable. Similar projects in Georgia, Illinois, and Kansas attest to this need.

\section{PROJECT DESCRIPTION}

Four action lines were followed in the project development:

1) digitization of aerial photographs and photomosaic indexes;

2) development of a GIS interface;

3) creation of instructional materials; and

4) creation of a Web site and integration of Products 1-3.

\section{Digitization of aerials and photomosaic indexes}

Scanning of the aerial photographs (tiles) began in November 2002 and continued through August of 2004. The photomosaic indexes were captured in four months on a large format camera.

Throughout the aerial tile scanning, photogrammetric glass targets were used to document distortion introduced by the various scanners. Although drum scanners that are photogrammetrically more accurate were considered, their cost precluded use in this project. Because original negatives were no longer available, distortions introduced by the photographic printing process were accepted, as were distortions introduced into the source image by pitch and yaw of the plane. Subsequent reviews of the scanned images showed that the amount of distortion was quite minimal and within the acceptable range.

Image capture of the $9 \times 9$ inch aerial tiles and the $20 \times 24$ inch photomosaic indexes adhered to the guidelines promulgated by the Cornell Department of Preservation and Conservation (see Digital Imaging for Library and Archives, Anne R. Kenny and Stephen Chapman, Ithaca, NY : Cornell University Library, 1996).

TIFF masters were the original capture format. Electronic archive masters are uncompressed TIFF files (ITU 6.0) at 100\% scale: the current de facto standard for electronic image archives. Aerial tile images were scanned at $615 \mathrm{dpi}$, 8-bit greyscale. Because digitized aerial photographs average approximately 29.9 MB, a compressed SID version of 1.3-1.5 MB was created for serving over the Web. SID images are served from a dedicated server at the Florida Center for Library Automation. Migration to the JPEG 2000 (Level 1: JP2) file format is planned.

Epson Expression 1640XL-SE and Microtek 9600XL and 9800XL flatbed scanners were used to capture the aerial tiles. For the larger photomosaic indexes, a planetary PhaseOne PowerPhase FX 4x5 inch digital camera back with a 10,500 pixel by 12,600 pixel scanning area and a 8-bit greyscale was used. The camera back is mounted on a planetary ZBE Satellite universal scanning system that is no longer manufactured. It includes a three turret mounted lenses \& bellows, a camera stand, and an automated control system for calibrated imaging. A Rodenstock Rodagon $135 \mathrm{~mm}$ professional enlarging lens (f/5.6-f/22)) with an AR- 
1 high aspect ratio filter was used for imaging. Two daylight balanced fluorescent Videssence ICELITE 360 light banks provided even illumination. Indexes were held in place during imaging by a Cobra-Pro vacuum easel powered by 2 Craftsman wet/dry shop vacuums. All of the index images were captured by and processed on a Macintosh Apple G4 with dual $1 \mathrm{GHz}$ processors, 1 GB RAM, and a 36GB SCSI hard drive. The Macintosh computer operates OS 10 with OS 9.2 subroutines for compatibility with Phase One imaging software. Final quality control is performed using Adobe Photoshop CS (v.8). TIFF images were processed with LizardTech's MrSid 1.3.1 to create servable SID images.

\section{Image Management}

The management of the 88,000 physical aerial tiles and the subsequent collection and processing of the scanned images were major challenges faced by this project. Each physical aerial tile was tracked from the time it was borrowed from the Map Library until the time it was returned. For each TIFF image created, several key pieces of data were collected: the scanner, the time of the scan, and the technician who performed the work. TIFF header information included bit-depth and resolution and was verified against project requirements. Every tile was post-processed for both image (e.g., gamma) correction and creation of webfriendly formats. Additionally, tile images were visually inspected to assure quality. Finally, each image was archived, and the web formats sent offsite via FTP to the image server at the Florida Center for Library Automation.

A programmer developed three different software tools to address these needs. The creation of a user-friendly front end allowed each physical tile to be tracked through the entire in-house process. As each physical tile was received, it was checked against a database, and then assigned to a technician for scanning. Once scanned, images were collected, processed, FTPed, and archived and each action was tracked in the application. Once all the tiles for a flight were complete, the tiles were returned en masse.

The second tool automated image collection from the disparate scanning locations, performed basic image manipulation for quality control, and stored collected data in the database. Image scans were stored in individual flight folders on local hard drives. As images were collected from drives, data related to the scanner and flight numbers were also stored in the database. This application also read the TIFF header of each image to ensure that the correct technical specifications, e.g., dpi, greyscale, were followed during scanning. Deviant parameters triggered error notifications.

The last tool used for processing images performed routine image corrections and prepared web format images on a dedicated computer. The processor performed histogram correction and SID creation for each image. Additional JPEG thumbnails were kept for visual quality control on the images. Each of the web formats was automatically sent to the FCLA web hosting site and the raw TIFF images packed into CD-size folders for local archiving. Finally, all of this data was stored in an aerials database and the aerial tiles returned to UF's Map \& Imagery Library. Cost saving accrued from these automated procedures reduced the project costs by $\$ 20,000$.

Each of the tiles captured has a record in an MS-SQL database. The database programmer collaborated with the Libraries' Systems Department and the GIS coordinator to create a webbased map interface. The interface permits searching by county, latitude and longitude, township/section/range, and year. These access points were suggested by the same group of 90 individuals who responded to the initial request concerning the need for the project. The site 
of the interface is accessed through the Aerial Photography: Florida home page at http://web.uflib.ufl.edu/digital/collections/FLAPI.

\section{GIS Interface}

To create the map interface, GIS technicians under the supervision of the GIS Coordinator used ERDAS Imagine software to geographically rectify and stitch together the multiple county mosaic index tiles. Individual aerial tiles were then hyperlinked to corresponding spatial points on the indexes.

The image below shows the interface that has been created. Each tile is represented by a green dot that turns yellow when selected. Users may select an area of interest by using zoom tools, by drawing spatial footprints, e.g., rectangles, polygons, or by searching the tile database. The individual tile is zoomable and can be viewed at a 1:1 ratio.

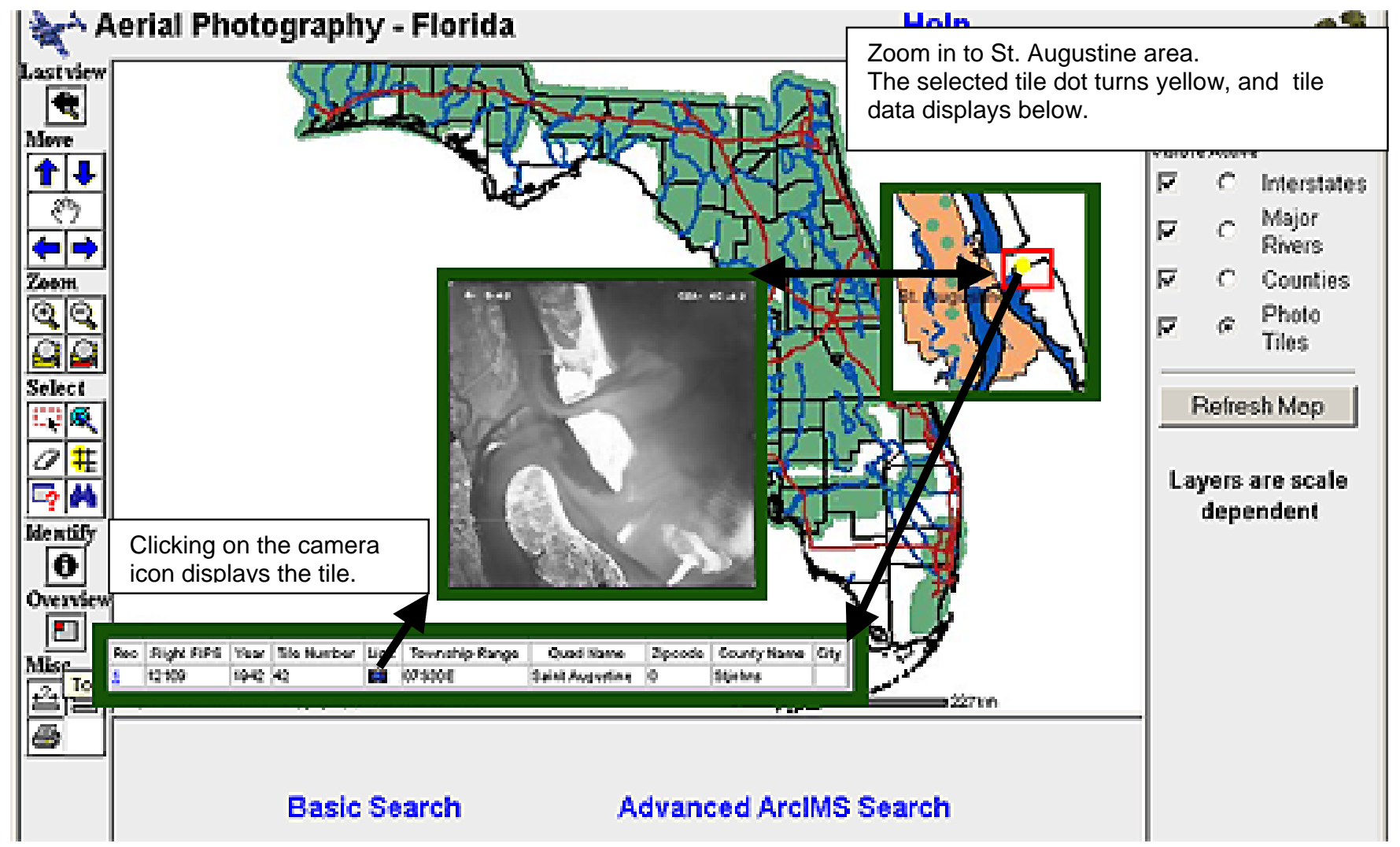

The spatial search engine, individual images, and metadata are integrated through the ESRI ARCIMS (Internet Map Server) software and served from a map server housed at the University of Florida Libraries' Systems Department. ESRI ArcGIS software is used to integrate other geospatial data layers, e.g., roads, rivers, political boundaries, etc. with the aerial index layers.

While initial programming efforts were directed at creating an interface that allowed the user to search by multiple access points (for example, by county and year), the built-in search functionalities of the ARCIMS software proved the most intelligible and functional approach to combining search terms for users already familiar with GIS applications. Additional revision is pending to make advanced searches more intelligible to the average user with no previous GIS 
experience. A quick search help screen was created to assist users in defining their search components.

\section{EDUCATIONAL/INSTRUCTIONAL MATERIALS}

Instructional modules were developed for elementary school students and for the general public. Modules completed to date include:

Interpreting Aerial photography [http://www.uflib.ufl.edu/digital/collections/FLAP/education/Interpreting/Interpret.htm] gives a general overview of how to interpret aerials.

\section{Spanish Explorers in the New World}

[http://www.uflib.ufl.edu/digital/collections/FLAP/education/Explorer/SPANISHEXPLORERS.pd f] (Grades 3-5) Reading/worksheet combination. This unit includes information on Christopher Columbus and Ponce De Leon's exploration of Florida.

Miami [http://www.uflib.ufl.edu/digital/collections/FLAP/education/Cities/Miami.htm ] (Grade 68) This unit discusses the evolution of Miami from the stone circles of the Tequesta to modern high rises. An introduction to aerial photos shows students how to track city growth.

\section{A Place in Time}

[http://www.uflib.ufl.edu/digital/collections/FLAP/Education/StAug/Placeintime.htm] provides a model of how to use aerial images to determine landscapes over time. Two images of St. Augustine Harbor one from 1942 and the other from 1960 show changing land use. The activity for this unit asks students to choose a feature in his/her own county and see how surrounding land use has changed over a period of years.

In additional to the educational components, eleven search guides http://web.uflib.ufl.edu/digital/collections/flap/Helpdetail/Howto.htm were developed to help users understand how GIS mapping interfaces function and to give instructions on using the site.

\section{USE OF THE SYSTEM}

Although the project has never formally been announced, use of the images has grown rapidly. 2003-2004 statistics collected by the Florida Center for Library Automation (FCLA) indicate 1,028 unique users had accessed the site. These users accounted for more than 398,600 manipulations of the aerial images. Manipulations are defined as both the initial display of an aerial image and zooming around the image itself.

The following three charts compare the usage of county aerial tiles for 2003 and 2004 . It should be noted that the preliminary aerial site became available in late 2003. The data collection for 2004 covers January through November 5, 2004. 
Email and phone contacts concerning aerial use continue to grow. The site has an FTP request form that is used to facilitate the transferring of SID images and occasionally TIFF images to requestors. Between May and November more than 1,200 images were transferred to requestors.

Alachua to Hardee County Aerials Used, 2003-2004 comparison

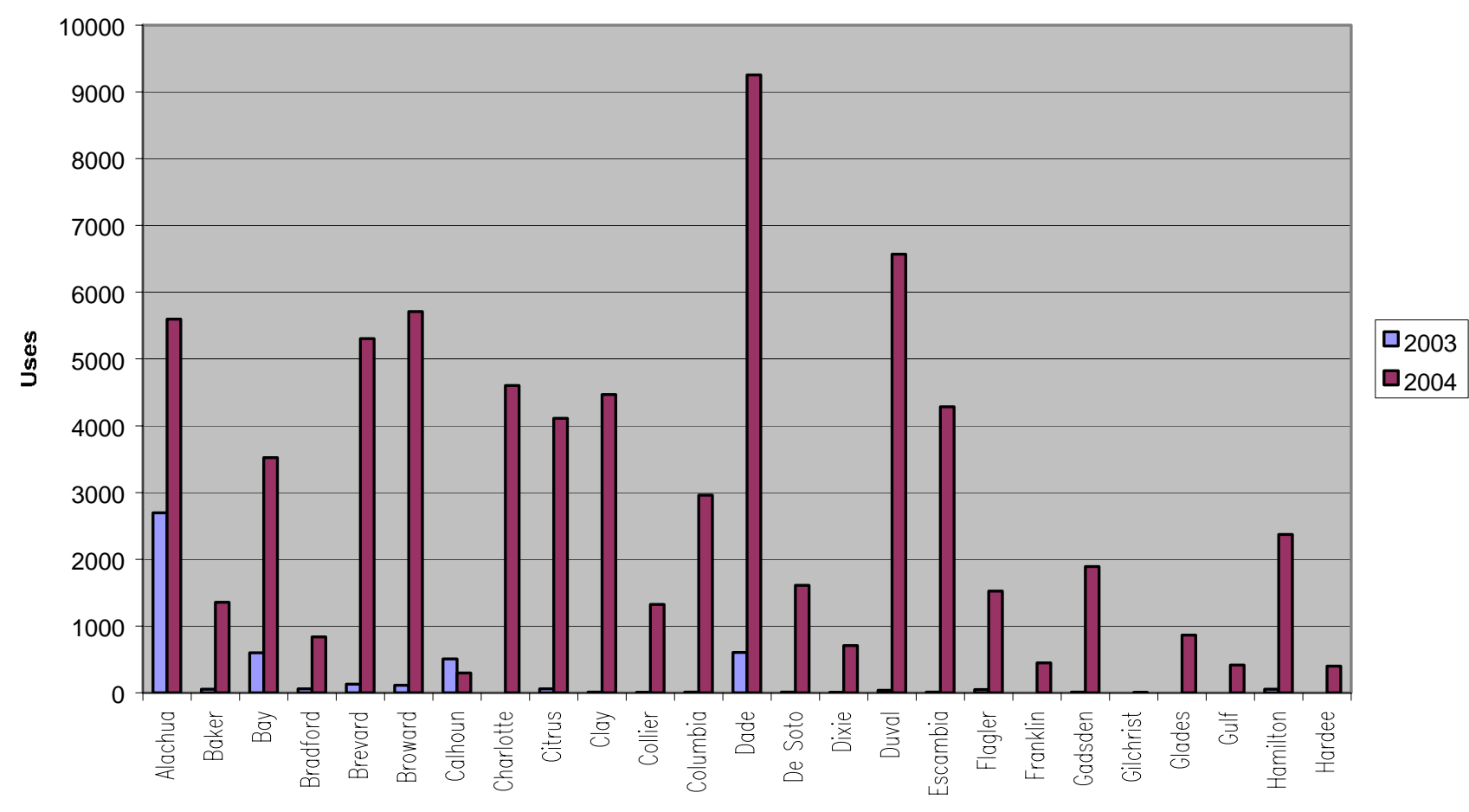

Counties

Hendry to Monroe County Aerials Used, 2003-2004 comparison

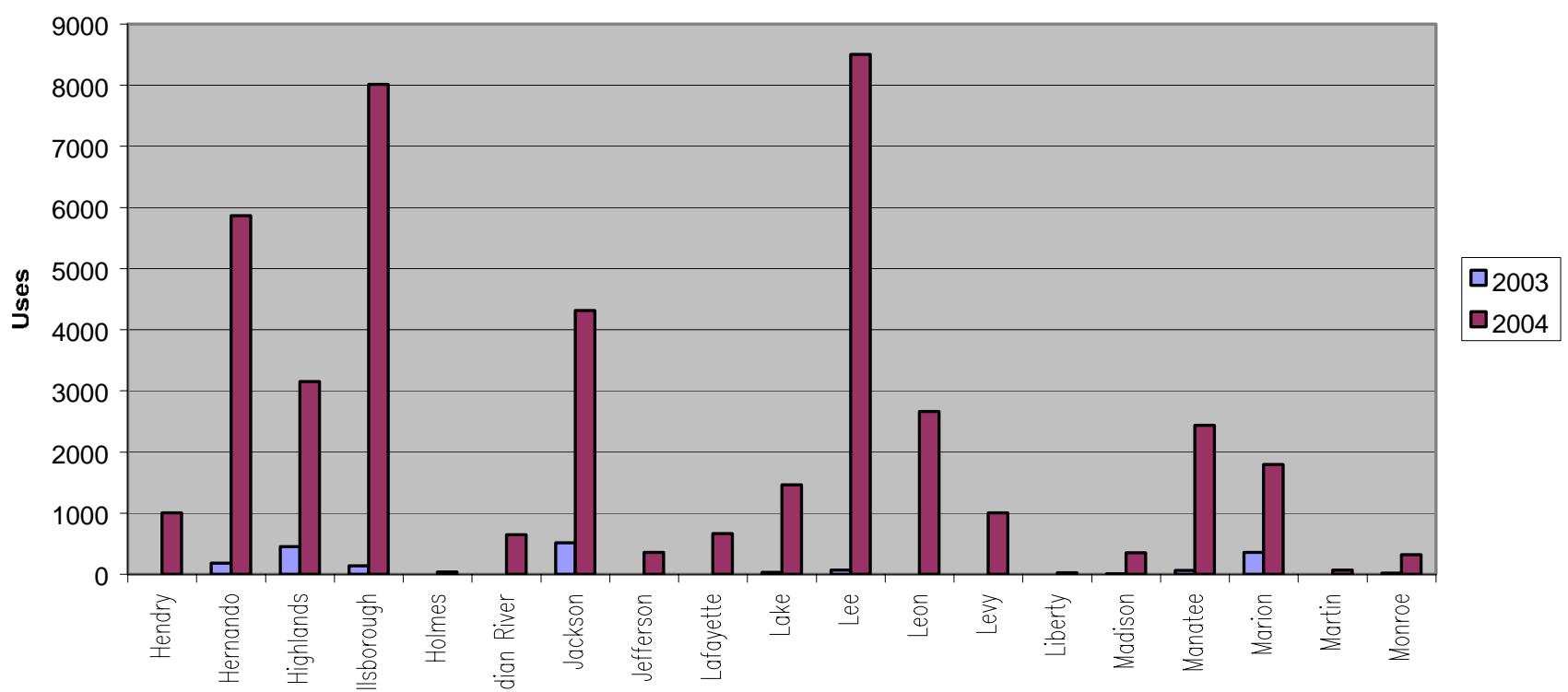

Counties 
Nassau to Washington County Aerials Used, 2003-2004 comparison

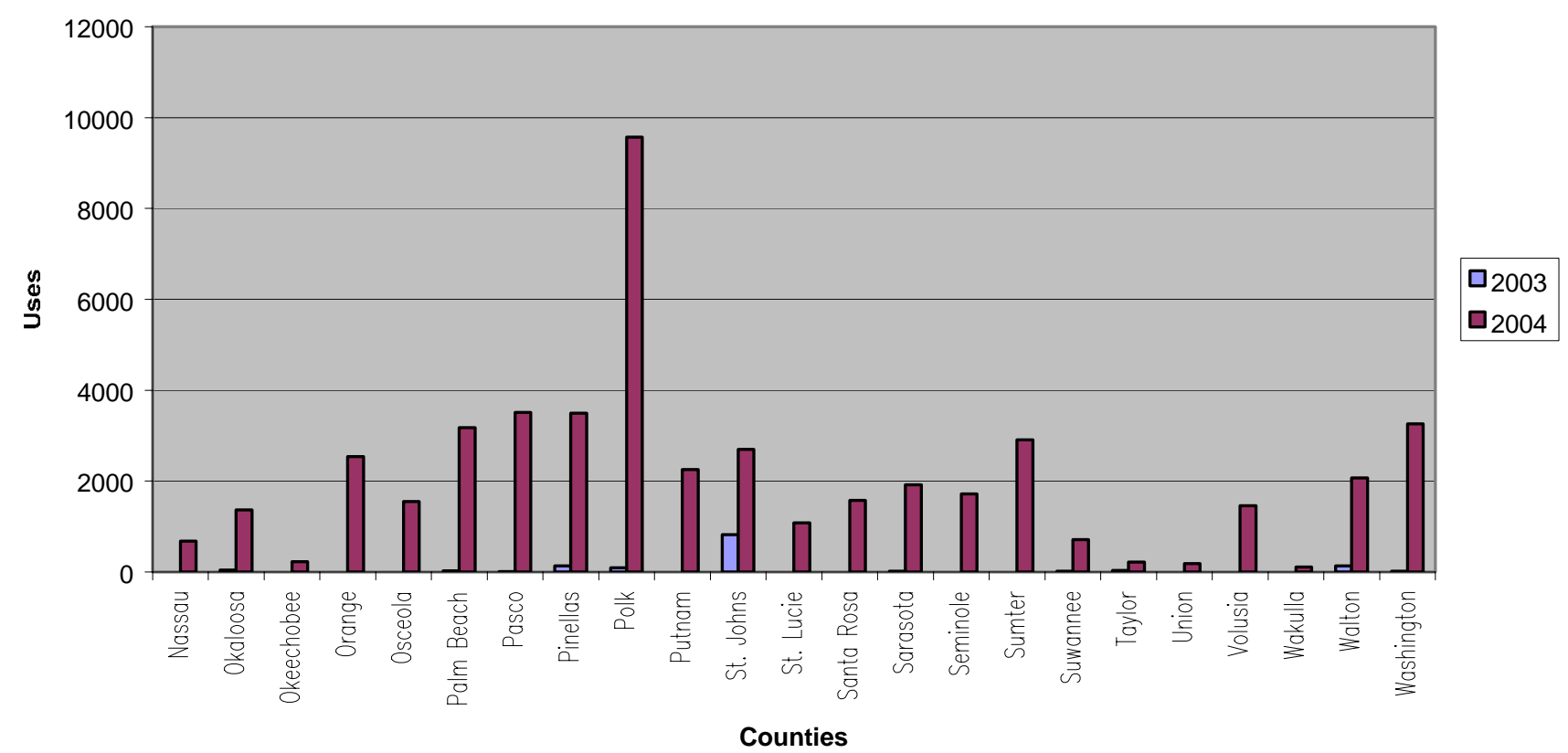

\section{FUTURE PLANS}

Although the GIS functionality is familiar to land use professionals, the project team has become aware of the difficulty it represents for the general public and K-12 audiences. This project was presented at the annual conference of the Florida Association for Media in Education and while there was great interest in the content, the interface proved too daunting for many of the attendees. In order to provide the broadest service to the citizens of Florida, the design of a second, less complex interface to the aerial collection is a high priority.

Expanded year coverage is also a priority. The completed U.S. Department of Agriculture aerial collection will include digitized aerials from 1971 through 1995: the starting date for the online collection of the Florida digital orthographic quarter quads http://data.labins.org/2003/MappingData/DOQQ/doqq.cfm.

Robert R. Terry, Agricultural Statistics Administrator, Commercial Citrus Inventory has given us permission to digitize and serve the aerial photographs taken as part of the Commercial Citrus Inventory. These images have been taken every two years since 1965 and document changes in citrus grove/land use. Currently there are 160 canisters of film containing approximately 24,000 images. Procedural modifications necessitated by these roll films are currently being tested. Additionally, many agencies that are using the USDA aerial collection have indicated a willingness to return georectified images and/or to provide images of tiles we are missing. Such collaboration will help us build a digital collection of significant value to the entire state. Automated methods of contribution and attribution of "trust" are being configured.

In terms of technical enhancements, the project team has identified several functionalities that need to be addressed: 
1) All data fields for any individual tile should be searchable and viewable;

2) The geospatial footprint of the tiles, currently points, should be buffered to a closer approximation of actual earth coverage*;

3) The georectified photomosaic indexes should be stitched together and be viewable as a viewable layer;

4) Features from the Geographic Names Information System (GNIS) should be added to the data layers;

5) More detailed transportation layers need to be added to help identify locations of interest; and

6) A publicly accessible FTP server needs to be developed so individual users with proper authorization can download needed high-resolution images.

\section{CONCLUSIONS}

It is most appropriate to conclude with comments from the actual users:

Our Division is actively restoring natural areas in the state of Florida. We have used the aerials to delineate native undisturbed areas (now disturbed) for restoration. We have also used the aerials in geo-rectified form and loaded them onto our GPS data loggers and navigated to disturbed areas (previously undisturbed) that were undetectable by any other means or data source. This site is and will be valuable to government agencies for the data that the imagery contains. The data site is easy to use and lets non-technical people access the data. Please keep the site and data collection effort up and going.

- GIS Coordinator at a state environmental agency

The Florida aerial images site has been indispensable to me for identifying potential research sites for examining the effects of land conversion on storage of soil carbon in South Florida. The website was useful in identifying available historical aerials, choosing the images most relevant to my study area, and having those images transferred to our organization. This site is an outstanding resource for researchers and land managers.

- Director of Research at a biological research laboratory

This site was extremely useful to my research on gopher tortoises. It allowed me to trace habitat changes and anthropogenic disturbance to a large number of study sites over the last 50-60 years. Being able to download all of the maps from one site saved me considerable time and effort.

- Graduate Student

\footnotetext{
* Georectification of individual tiles or the definition of bounding boxes would be idea, with sufficient funding.
} 